\title{
A functional movement screening of college students performing Pilates exercise
}

\author{
Su Yeon Roh, PhD \\ Department of Exercise Rehabilitation, Gachon University, Incheon, Rep. of Korea
}

\begin{abstract}
Background: With the emergence of functional movement in the study of athleticism, Pilates exercise based on the activation of the body core is attracting much attention.

Objective: This study aimed to investigate the changes in functional movement after performing Pilates exercise.

Methods: A total of 31 college students at university $\mathrm{K}$ in seoul were included in this study. These students performed a 90 -minute

Pilates exercise twice a week for 16 weeks. Frequency analysis and paired t-test were performed using IBM SPSS ver. 25.0 (IBM Corp., Armonk, NY, USA).

Results: All the seven factors of functional movement screen (FMS) showed statistically significant results.

Conclusion: Considering that the levels of all the seven factors of FMS improved after performing Pilates exercise, Pilates exercise is considered superior in improving functional movement.
\end{abstract}

Keywords: college students; function; functional movement screen; physical ability; Pilates

\section{Introduction}

The interest in Pilates exercise continues to grow due to the current social trend of favoring a beautiful appearance and a slim body shape. Moreover, Pilates exercise recognizes the human body and mind as one and cultivates them mutually and organically to make the body supple and balanced and to strengthen the small muscles, making the body line beautiful [1]. Additionally, Pilates exercise is a full-body exercise program that strengthens the muscles in the deepest part of the body while balancing the muscles, and that helps one attain correct posture with correct body alignment without causing body pain [2]. Most of Pilates's original postures consisted of core exercises using mats. After performing the Pilates exercise among various groups, including middle-aged women [3], college students majoring in dance [4], and elderly women [5], it was proven that the Pilates exercise program has an excellent effect in activating the body core, which improves the bodily stability and increases the inherent receptive senses to adjust the balance, posture, and movement. Moreover, it improves the functional movement, which enhances the motor response and effectively improves the overall body function [6].

Functional movement refers to the physical ability to assume an efficient posture by appropriately coordinating mobility and stability while performing a basic movement pattern. To achieve this, it is necessary to sufficiently secure such factors as core stability and range of motion [7]. Physical stability, which ensures control of the body in a well-balanced manner, means the activation of the muscles in the body core. Loss of muscle function, associated with limb movements, diminishes 
the function of movement and degrades the qualitative ability of such movement [8]. If any problem arises because of these factors, the balance between mobility and stability is altered, thereby potentially triggering the compensation mechanism and hence raising the risk of injury. Thus, to identify the functional movement level as a test to distinguish the aforementioned factors, the functional movement screen (FMS) scale is used to compare the body conditions before and after Pilates exercise [7]. In this regard, several studies have been conducted to determine the effects of combined training [9], proprioceptive core exercise [10], core stabilization exercise [11,12], and balance training [13].

According to a previous study [7], the seven tests of FMS can be classified into the following two key categories: primitive movement and higher movement. Primitive movement is then divided into mobility (shoulder mobility, active straight leg raise) and stability (trunk stability push-up, rotary stability). When the primitive movement is corrected/improved in the order of mobility and stability, it is said that the higher movement changes into a functional pattern. The study also suggests that if one moves to a higher movement without correcting one's primitive movement, it is probable that functional impairment due to the compensation function will be notable.

Therefore, this study aimed to repeat this previously published functional movement test [7] by conducting the Pilates exercise program, which is highly effective in improving flexibility and core strength, among university students for 16 weeks. Through this, the author intended to verify the effects of the Pilates exercise program in terms of increasing the body flexibility, correcting the posture, and increasing mobility and balance for an improved physical functioning. Additionally, through this effective verification, Pilates exercise program can be considered the best program to improve obesity issues and can be an effective way to achieve a beautiful and balanced body line by applying this exercise program for core activation and functional movement.

\section{Materials and methods}

\section{Study subjects}

A total of 31 students (8 females, 23 males) of university $\mathrm{K}$ in Seoul who participated in the Pilates exercise program and who voluntarily participated in the study after it was explained to them were selected as the study subjects. Their physical characteristics were assessed before the execution of the 90-minute Pilates exercise program as shown in Table 1, which was con-
Table 1. Physical characteristics of the study subjects

\begin{tabular}{lrr}
\hline \multicolumn{1}{c}{ Variable } & \multicolumn{1}{c}{ Pretest } & \multicolumn{1}{c}{ Posttest } \\
\hline Height $(\mathrm{cm})$ & $170.194 \pm 5.759$ & $170.226 \pm 5.778$ \\
Weight $(\mathrm{kg})$ & $67.365 \pm 9.940$ & $65.400 \pm 9.883$ \\
Waist $(\mathrm{inch})$ & $31.226 \pm 2.872$ & $30.807 \pm 3.007$ \\
Hip $($ inch $)$ & $35.645 \pm 1.959$ & $35.503 \pm 1.989$ \\
BMI $\left(\mathrm{kg} / \mathrm{m}^{2}\right)$ & $23.071 \pm 2.936$ & $22.440 \pm 2.664$ \\
\hline
\end{tabular}

BMI, body mass index.

ducted twice a week for 16 weeks. After the conclusion of the exercise program, the physical characteristics of the study subjects were reassessed.

\section{Measurement}

An FMS kit (Functional Movement Systems, Inc., Chatham, VA, USA) was used for measurement and evaluation. It is a standardized measurement tool that evaluates dynamic and functional movements using seven measurement operations. The flexibility, mobility, posture control, and balance of the upper and lower limbs can be evaluated using this tool. Developed by Gray [7], this equipment has a total of 21 scores, with individual scores of 7 actions ranging from 0 to 3 . The possible risk of injury in daily life is stated to be less than 14 points. According to Gray [7], the equipment helps improve the quality of the correct movement patterns by evaluating and analyzing the dysfunction and imbalance of the body. The seven measurement operations are as follows: (1) deep squat, (2) hurdle step, (3) inline lunge, (4) shoulder mobility, (5) active straight leg raise, (6) trunk stability push-up, and (7) rotary stability.

\section{Statistical analysis}

IBM SPSS Statistics ver. 25.0 (IBM Corp., Armonk, NY, USA) was used in this study in performing paired t-tests and frequency analysis and in comparing the pre- and posttest values according to the purpose of the analysis. A p-value of $<0.05$ was considered statistically significant.

\section{Experimental procedures}

The researcher conducted the study and instructed the students to perform the Pilates exercise program during their voluntary participation in the study. A total of 31 subjects voluntarily participated in this study, and they were informed on the research process at the beginning of the semester before the research protocol commenced and eventually signed the consent form. The general characteristics and FMS of the subjects who participated in this study were assessed before they participated 
in the exercise program. After the 16th week of the program execution, the subjects' general characteristics were reassessed to identify their FMS. During the exercise program, the researcher selected 15 key actions from the original workout of Joseph Pilates that can easily be accessed by beginners and can correct the body shape considering the subjects' characteristics. The exercise program that was used in this study is shown in Table 2.

\section{Results}

\section{Detailed scoring by action}

Table 3 summarizes the pre- and posttest scores for each action. Scores for the hurdle step, shoulder mobility, deep squat, inline lunge, active straight leg raise, trunk stability pushup, and rotary stability were $1.387 \pm 0.495$ and $1.903 \pm 0.539$; $1.290 \pm 0.461$ and $1.871 \pm 0.499$, indicating a statistically significant difference at $\mathrm{p}<0.001 ; 1.871 \pm 0.427$ and $2.258 \pm 0.445 ; 1.451 \pm 0.568$ and $2.032 \pm 0.706 ; 1.677 \pm 0.599$ and $2.065 \pm 0.574 ; 1.419 \pm 0.564$ and $1.708 \pm 0.461$, indicating a statistically significant difference at $\mathrm{p}<0.01$; and $1.419 \pm 0.502$ and $1.613 \pm 0.495$, indicating a statistically significant difference at $\mathrm{p}<0.05$, respectively.

\section{Scoring by functional item}

Table 4 shows the pre- and posttest scores of each functional item. Scores for the higher movement (deep squat, hurdle step, inline lunge), mobility (shoulder mobility, active straight leg raise), and stability (trunk stability push-up, rotary stability) were $1.570 \pm 0.367$ and $2.065 \pm 0.425 ; 1.484 \pm 0.418$ and $1.968 \pm 0.446$, indicating a statistically significant difference at $\mathrm{p}<0.001$; and $1.419 \pm 0.430$ and $1.661 \pm 0.351$, indicating a statisti-

Table 2. Pilates exercise program

\begin{tabular}{clcc}
\hline Stage & \multicolumn{1}{c}{ Type } & $\begin{array}{c}\text { Repetition/ } \\
\text { set }\end{array}$ & $\begin{array}{c}\text { Time } \\
\text { (min) }\end{array}$ \\
\hline Warm-up & $\begin{array}{l}\text { Breathing-maximizing capacity, } \\
\text { footwork, hugging the knees, } \\
\text { supine knee side to side, circles, } \\
\text { pelvic clock, bridging }\end{array}$ & $10 / 3$ & 10 \\
Mat & $\begin{array}{l}\text { Hundred, single leg circle, rolling } \\
\text { pilates } \\
\text { like a ball, single leg stretch, } \\
\text { double leg stretch, single straight } \\
\text { leg stretch, double straight leg } \\
\text { stretch, crisscross, spine stretch } \\
\text { forward, spine twist, saw, side } \\
\text { leg lift, side leg circle, swan, } \\
\text { single leg kick, double leg kicks, }\end{array}$ & & \\
side mermaid, kneeling side \\
kick, star, plank
\end{tabular}

cally significant difference at $\mathrm{p}<0.01$, respectively.

\section{Discussion}

This study aimed to investigate the effects of the Pilates exercise program in improving the functional imbalance and functional movement of college students for 16 weeks. The following discussions are presented based on the clinical verification results of the exercise program's effectiveness.

First, there was a significant difference between the pre- and

Table 3. Detailed functional movement screen scores

\begin{tabular}{lccc}
\hline \multicolumn{1}{c}{ Variables } & Mean \pm SD & t & p-value \\
\hline Deep squat & & $-3.860^{* *}$ & 0.001 \\
\hline Pretest & $1.871 \pm 0.427$ & & \\
\hline Posttest & $2.258 \pm 0.445$ & & \\
Hurdle step & & $-5.043^{* * *}$ & 0.000 \\
\hline Pretest & $1.387 \pm 0.495$ & & \\
\hline Posttest & $1.903 \pm 0.539$ & & \\
\hline Inline lunge & & $-3.815^{* *}$ & 0.001 \\
\hline Pretest & $1.451 \pm 0.568$ & & \\
\hline Posttest & $2.032 \pm 0.706$ & & \\
\hline Shoulder mobility & & $-5.211^{* * *}$ & 0.000 \\
\hline Pretest & $1.290 \pm 0.461$ & & \\
\hline Posttest & $1.871 \pm 0.499$ & & \\
\hline Active straight leg raise & & $-3.860^{* *}$ & 0.001 \\
\hline Pretest & $1.677 \pm 0.599$ & & \\
\hline Posttest & $2.065 \pm 0.574$ & & \\
\hline Trunk stability push-up & & $-3.057^{* *}$ & 0.005 \\
\hline Pretest & $1.419 \pm 0.564$ & & \\
\hline Posttest & $1.708 \pm 0.461$ & & \\
\hline Rotary stability & & $-2.257^{*}$ & 0.031 \\
\hline Pretest & $1.419 \pm 0.502$ & & \\
\hline Posttest & $1.613 \pm 0.495$ & & \\
\hline * $<0.05, * * p<0.01,{ }^{* * *}$ p $<0.001$. & & & \\
\hline & & & \\
\hline
\end{tabular}

Table 4. Functional item score of functional movement screen

\begin{tabular}{lccc}
\multicolumn{1}{c}{ Variable } & Mean \pm SD & t & p-value \\
\hline Higher movement & & $-5.498^{* * *}$ & 0.000 \\
Pretest & $1.570 \pm 0.367$ & & \\
Posttest & $2.065 \pm 0.425$ & & \\
Primitive movement & & & \\
Mobility & & $-5.303^{* * *}$ & 0.000 \\
Pretest & $1.484 \pm 0.418$ & & \\
Posttest & $1.968 \pm 0.446$ & & \\
Stability & & $-3.503^{* *}$ & 0.001 \\
Pretest & $1.419 \pm 0.430$ & & \\
Posttest & $1.661 \pm 0.351$ & & \\
\end{tabular}

${ }^{* *} \mathrm{p}<0.01,{ }^{* * *} \mathrm{p}<0.001$. 
posttest scores in the higher-movement program. A previous study also proved that stabilizing the pelvis and the body core improves functional movement, supporting the result of this study [14]. On the contrary, according to another study, there was no significant difference in the deep squat and inline lunge scores as a result of the execution of the program using the modified FMS-based muscle training [15]. In particular, the reason why the hurdle step and inline lunge actions improved in this study is because the side leg lift, side leg circle, and kneeling side kick actions of the Pilates exercise program stabilized the pelvis, thereby confirming that the action involves the frequent engagement of the mesogluteal muscle, which ensures the balance of the lower limbs. To induce a functional pattern in which the body core is activated and the limbs are moved, actions such as double leg stretch and double straight leg stretch should precede the aforementioned actions.

Second, there was a significant difference in the mobility and stability programs of the primitive movement before and after the program execution. After conducting a 4-week selfstretching exercise of female dancers, Lee [16] reported that their hip flexion significantly increased, which is in line with the results of another study [17], which reported, after conducting a mobilization test including fascia relaxation, thoracic spine extension, and thoracic rotation among female college students, that the level of FMS shoulder mobility improved. Although many researchers have tested various methods, such as the correction exercise program [18], core stability training [11], and complex training [9], there was no significant improvement in shoulder mobility, indicating that the exercise program that was executed had no effect. The reason that the results of this study are contrary to those of the previous studies is that rolling using a ball relaxes the peripheral muscles of the thoracic vertebrae, the swan exercise helps improve the extension ability of the thoracic spine, the spine stretch forward exercise improves the function of the shoulder girdle, and the spine twist and saw exercises increase the thoracic operability. It is also believed that the improvement in the level of the active straight leg raise exercise is attributable to the fact that the single leg stretch, single straight leg stretch, and single leg circle exercises involve flexion of one hip while the other hip is flexed, contributing to the flexibility and separation of the hip joint.

The motions of the Pilates sitting position, which are consistent with the motions proposed by another study [19] to elongate the posterior surface line, help relieve the fascia between the shoulder and hip joints, the oblique sling system, thereby prompting the authors to conclude that they resulted in a multi- dimensional exercise effect. On the contrary, Ju and Park (2015) [10] conducted a proprietary water-based core exercise program among college athletes but observed no significant difference in rotary stability. The reason why the results of such studies are different from those of this study is that the repetition of Pilates's side mermaid, star, and plank movements, which are similar to the trunk stability push-up exercise, had a positive effect. It can also be concluded that rotary stability, which requires the stretching of the back, is connected to the motion line of the crisscross action of the Pilates.

The results of this study are summarized as follows. Whereas the previous studies $[9,11,18]$ failed to improve the detailed FMS scores of the seven motions of the Pilates exercise program prepared for this study by a statistically significant margin, this study successfully improved all seven motions of the Pilates exercise program derived from Joseph Pilates, prompting the authors to conclude that the Pilates exercise program can provide a basis for the improvement of physical imbalance and functional movement. Moreover, this study contributes to the probable application of the Pilates exercise program based on Joseph Pilates's original workout that is a potential approach manage obesity and achieve a beautiful and balanced body. However, a follow-up study is necessary to investigate any sexrelated difference in the performance of Pilates exercise program by recruiting more subjects. Moreover, it would be important to compare the Pilates exercise program with other training methods in the future follow-up studies.

\section{Conflicts of interest}

The author has nothing to disclose.

\section{References}

1. Latey P. Modern Pilates: the step by step, at home guide to a stronger body. Crows Nest: Allen and Unwin; 2001.

2. Kendall FP. Muscles, testing and functions with posture and pain. Baltimore, MD: Lippincott Williams \& Wilkins; 2005. p. 31-9.

3. Lee J, Jeong IS. Effects of pilates-based core-strengthening exercise on muscle activities in middle-aged women. Korean J Sports Sci 2017;26:1377-88.

4. Park SJ, Kim HN, Jo JH. The effects of the core strenghteningpilates exercise on the performer's physical self-perception and performance confidence of college students majoring in dance. Off J Korean Soc Dance Sci 2013;30:107-21. 
5. Hong SY, Lee WY, Kim MR. Effect of 12-weeks pilates core balance training on bone density and isokinetic muscular function of elderly women. Korean J Phys Educ 2018;57:585-97.

6. Choi JH, Shin WS, Noh KT, Yeon PS. Effects of acute forest walking exercise on blood glucose of IGT, NIDDM in the Elderly. J Korean For Soc 2010;99:47-51.

7. Gray C. Movement: functional movement systems. Seoul: Daesung Medical Books; 2013.

8. Verheyden G, Vereeck L, Truijen S, Troch M, Herregodts I, Lafosse C, et al. Trunk performance after stroke and the relationship with balance, gait and functional ability. Clin Rehabil 2006;20:451-8.

9. Lee JW, Zhang SA, Lee JK. Effects of combined training on the FMS Score in woman rugby national players. J Korea Acad Ind Coop Soc 2015;16:7439-46.

10. Ju SB, Park KD. The effects of proprioceptive core exercise of short-term period on lumbar FMS and isokinetic muscle function in sport player with chronic back pain. Korea J Sports Sci 2015;24:1543-51.

11. Kim SH, So WY, Kim JY. Effect of 8-week core stabilization training on skill-related physical fitness and Functional Movement Screen (FMS) test scores in college soccer players. Korea J Sports Sci 2016;25:1473-83.

12. Park JM, Kim KR. Effects of core stability exercises on balance abilities and FMS(Functional Movement Screen) in elementary school baseball players. J Learn Centered Curric Instr 2017;17:279-91.

13. Park JM, Kim KL. Effects of balance training on posture stability and functional movement screen in elementary school alpine skiers. J Learn Centered Curric Instr 2017;17:579-93.

14. Kim GW. Effects of functional muscle training program based FMS(Functional Movement Screen) on muscle function and balance in 60s elderly female [thesis]. Seoul: Dongduk Women's University; 2018.

15. Kim GW, Kim CS. Effects of functional muscle training based FMS on muscle function and body balance in 60s elderly female. Korean Soc Living Environ System 2018;25:309-21.

16. Lee HJ. A study on the result that the self stretching affected danseuse's flexible hip joint. Korean J Danc Res 2005;5:69-77.

17. Kang HJ, Gong SM, Jung HJ, Kim BS. Effect of an integrated exercise program that combines the thoracic mobility exercises on kyphotic angle, pain and dysfunction, functional movement. Korea J Sports Sci 2015;24:1265-75.

18. Jeon JY. Effects of 12-week corrective exercise program on functional movement of female field hockey player [thesis]. Seoul: Sungshin Women's University. 2018.

19. Myers TW. Anatomy trains: myofascial meridians for manual and movement therapists. Seoul: Elsevier; 2012. 